\title{
Potentiating Effects of Calcium Chelators on Basal and Stimulated Aldosterone Production by Bovine Adrenal Glomerulosa Cells In Vitro
}

\author{
TOSHIKAZU KIGOSHI, HIROSHI OKAMOTO, TAKASHI ISHII, TOMOHIKO ITO, \\ FumitaKe HOTTA, MitsuTAKa KITAZAWA, MAKOTO NISHIZAWA, \\ SHIGERU NAKANO, SHINPEI MORIMOTO*, AND KENZO UCHIDA \\ Division of Endocrinology, Department of Internal Medicine, and \\ *Medical Research Institute, Kanazawa Medical University, Ishikawa 920-02, Japan
}

\begin{abstract}
We previously reported the potentiation of basal aldosterone production by the addition of the calcium chelator ethyleneglycol-bis-( $\beta$-aminoethyl ether)- $\mathrm{N}, \mathrm{N}, \mathrm{N}^{\prime}, \mathrm{N}^{\prime}$-tetraacetic acid (EGTA) to an extracellular solution of bovine adrenal glomerulosa cells in vitro. To assess whether the addition of the calcium chelators ethylenediamine- $N, N, N^{\prime}, N^{\prime}$-tetraacetic acid (EDTA) and EGTA can potentiate basal and stimulated aldosterone production, we compared the effect of EDTA with that of EGTA on basal and the agonist (potassium; $8 \mathrm{mM}$, angiotensin II; $10 \mathrm{nM}$, ACTH; $10 \mathrm{nM}$ )-stimulated aldosterone production by the cells in vitro. These two chelators lowered the extracellular ionized calcium $\left(\left[\mathrm{Ca}^{2}+\right]_{0}\right)$ concentration in a similar manner. The levels of basal and the agonist-stimulated aldosterone production in the presence of EDTA $(1 \mathrm{mM})$ and EGTA $(1 \mathrm{mM})$ were significantly $(P<0.01$ or less $)$ increased when compared with those in the absence of EDTA and EGTA, respectively. These results show that the addition of EDTA and EGTA to an extracellular solution potentiates basal and the agoniststimulated aldosterone production in vitro. Although an increase in basal aldosterone production in the presence of EDTA $(1 \mathrm{mM})$ and EGTA $(1 \mathrm{mM})$ was completely inhibited by the voltage-dependent calcium channel antagonist nifedipine $(1 \mu \mathrm{M})$ or the calmodulin antagonist pimozide $(1 \mu \mathrm{M})$, the potentiation of the agonist-stimulated aldosterone production does not seem to be induced by $\mathrm{Ca}^{2+} /$ calmodulin-dependent nor cAMP-dependent systems. These findings suggest that calcium chelators such as EDTA and EGTA may possess activating effect on basal and stimulated aldosterone production in bovine adrenal glomerulosa cells.
\end{abstract}

Key words: Extracellular calcium, Aldosterone, EGTA, EDTA, Adrenal glomerulosa cells

(Endocrine Journal 44: 335-339, 1997)

ADRENAL glomerulosa cells is thought to be one of the good models for clarifying the machanism of intracellular signal transduction systems activated by calcium ion [1-5]. In a calcium-free medium, angiotensin II (AII), potassium and

\section{Received: April 30, 1996}

Accepted: December 2, 1996

Correspondence to: Dr. Toshikazu KIGOSHI, Division of Endocrinology, Department of Internal Medicine, Kanazawa Medical University, 1-1 Daigaku, Uchinadacho, Kahokugun, Ishikawa 920-02, Japan
$\mathrm{ACTH}$, three main regulators of aldosterone production, do not stimulate aldosterone production [1-3, 6]. Our recent report [7], however, showed that the addition of the calcium chelator ethyleneglycol-bis-( $\beta$-aminoethyl ether)- $\mathrm{N}, \mathrm{N}, \mathrm{N}^{\prime}, \mathrm{N}^{\prime}$ tetraacetic acid (EGTA) to an extracellular solution (less than $1.2 \mathrm{mM}$ ) stimulates basal aldosterone production, in part, through the activation of voltage-dependent calcium channels and calmodulin-dependent mechanisms in bovine adrenal glomerulosa cells in vitro.

The present study was designed to compare the 
effect of ethylenediamine- $N, N, N^{\prime}, N^{\prime}$-tetraacetic acid (EDTA) with that of EGTA on basal and stimulated aldosterone production in bovine adrenal glomerulosa cells in vitro.

\section{Materials and Methods}

EDTA, EGTA, pimozide and HEPES (N-2hydroxyethylpiperazine- $\mathrm{N}^{\prime}$-2-ethanesulfonic acid) were obtained from Sigma Chemical Co. (St. Louis, MO, USA). Crude collagenase (type I) was purchased from Worthington Biochemical Corp. (Freehold, NJ). Bovine serum albumin (fraction V) was obtained from Peptide Institute Inc. (Tokyo, Japan). Synthetic [Ile ${ }^{5}$ AII and nifedipine were purchased from Wako Pure Chemical Industries (Tokyo, Japan). Synthetic $\alpha \mathrm{ACTH}^{1-24}$ was obtained from Organon Diagnostics (West Orange, NJ, USA). The protein kinase inhibitor 1(5-isoquinolinesulfonyl)-2-methylpiperazine dihydrochloride (H7) was obtained from Seikagaku Corp. (Tokyo, Japan). All other chemicals were of analytical grade.

Bovine adrenals were obtained from a local abattoir. Isolated adrenal glomerulosa cells were prepared by a collagenase digestion technique as previously described [8]. Dispersed cells were suspended in medium 199 (Gibco) containing $4 \mathrm{mM}$ potassium chloride, $1.85 \mathrm{mM}$ calcium chloride, 16 $\mathrm{mM}$ sodium bicarbonate and $0.1 \%(\mathrm{w} / \mathrm{v})$ bovine serum albumin to a uniform concentration of $1 \times$ $10^{5} \mathrm{cells} / \mathrm{ml}$. EDTA and EGTA were dissolved in 20 mM HEPES buffer solution (stock solution; 100 $\mathrm{mM}, \mathrm{pH}$ was adjusted to 7.4 with $\mathrm{NaOH}$ ). After adding the stock solution to medium 199, $\mathrm{pH}$ in the incubation medium was adjusted by continuous superfusion with a gas mixture of $95 \% \mathrm{O}_{2}-5 \% \mathrm{CO}_{2}$ ( $1 \mathrm{l} / \mathrm{min})$. Cell viability, determined by trypan blue exclusion prior to and at the end of the experiments, was approximately $90 \%$. One milliliter aliquots were then incubated with the chelators (from $0.2 \mathrm{mM}$ to $1.6 \mathrm{mM}$ ) or/and the stimuli (potassium; $8 \mathrm{mM}$, AII; $10 \mathrm{nM}$, ACTH; 10 $\mathrm{nM})$ for $2 \mathrm{~h}$ at $37^{\circ} \mathrm{C}$ under $95 \% \mathrm{O}_{2}-5 \% \mathrm{CO}_{2}$ gas. The levels of $\mathrm{pH}$ in the incubation media before and 2 $\mathrm{h}$ after the addition of $1 \mathrm{mM}$ EGTA $(7.4 \pm 0.1 ; \mathrm{n}=3$ and $7.4 \pm 0.1 ; n=3$, respectively) were determined with a digital $\mathrm{pH}$ meter (HM-30V, TOA Electronics Ltd., Japan). In some experiments, after the cells were prepared in a calcium-free solution (modified Krebs-Ringer bicarbonate solution without calcium; $0.1 \%(\mathrm{w} / \mathrm{v})$ bovine serum albumin, $0.1 \%(\mathrm{w} / \mathrm{v})$ glucose and $4 \mathrm{mM}$ potassium), the effect of adding an increased amount of calcium chloride to the calcium-free solution on basal aldosterone production in the absence or presence $(1 \mathrm{mM})$ of EGTA was studied. The cells were then precipitated by centrifugation, and the media were stored at $-20{ }^{\circ} \mathrm{C}$ to measure the aldosterone and electrolyte concentrations. Aldosterone levels in the incubation media were determined by radioimmunoassay as previously described [8].

Cyclic AMP levels in the incubation media were determined by radioimmunoassay. Ionized calcium levels in the incubation media (corrected for $\mathrm{pH}$ 7.4) were measured with a NOVA 8 calcium analyzer (NOVA Biomedical, USA). Sodium, potassium, chloride and magnesium levels in the incubation media were determined with an autoanalyzer (Hitachi 7450E, Japan). The levels of osmolarity in the incubation media before and after the addition of the chelators, determined by the depression-of-freezing-point method (model OSA21, Nikkiso, Tokyo, Japan), were not altered. Results are expressed as the mean \pm SEM. Statistical significance of differences between the two groups was made by unpaired Student's $t$-test and is indicated by the two-tailed $P$ value.

\section{Results}

Figure 1 shows the changes in aldosterone production in the presence of graded concentrations of the calcium chelators, EDTA and EGTA, in the incubation media. Levels of basal aldosterone production were gradually increased when adrenal glomerulosa cells were incubated with graded concentrations of the calcium chelators up to $1 \mathrm{mM}$. The levels of aldosterone production in the presence of more than $1.2 \mathrm{mM}$ of EDTA and EGTA were similar to those in the absence of these two chelators in the incubation media. When the cells were prepared in a calcium-free solution, the levels of basal aldosterone production were noticeably increased to a maximum in the presence of $1 \mathrm{mM}$ EGTA and $1.6 \mathrm{mM}$ calcium chloride (559.6 $\pm 77.0 \mathrm{pg} / 10^{5}$ cells, $P<0.01$ vs. corresponding basal value without calcium chloride; $95.3 \pm 9.7 \mathrm{pg} / 10^{5}$ 


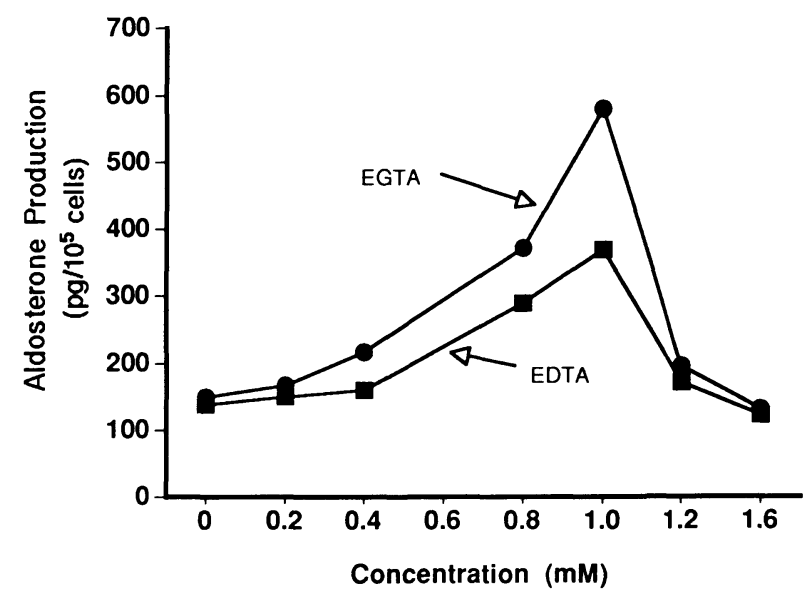

Fig. 1. Effects of the calcium chelators (EDTA and EGTA) on basal aldosterone production in bovine adrenal glomerulosa cells. Values are expressed as the means of duplicated samples from a representative experiment.

cells, $n=3$ ), and slightly but significantly increased to a maximum in the presence of $0.6 \mathrm{mM}$ calcium chloride without EGTA in the incubation medium (159.0 $\pm 10.0 \mathrm{pg} / 10^{5}$ cells, $P<0.05$ vs. corresponding basal value without calcium chloride; $91.3 \pm 10.6$ $\mathrm{pg} / 10^{5}$ cells, $\mathrm{n}=3$ ). Cyclic AMP levels in the incubation media were not detectable in the presence of graded concentrations of the chelators. The EDTA-induced increase in aldosterone production was inhibited by the voltage-dependent calcium channel antagonist nifedipine and the calmodulin antagonist pimozide in a dosedependent manner with half-maximum inhibitory concentrations of $10 \mathrm{nM}$ and $50 \mathrm{nM}$, respectively. This increase was completely inhibited at a concentration of $1 \mu \mathrm{M}$ of nifedipine or pimozide, but was unaffected at any concentration up to 10 $\mu \mathrm{M}$ of $\mathrm{H} 7$ tested. These data were similar to the case of EGTA [7].

The levels of electrolytes in the incubation media in the presence of graded concentrations of EGTA and EDTA are shown in Table 1. The sodium concentration in the incubation medium was not significantly altered after the administration of these chelators. The ionized calcium concentration in the incubation medium gradually decreased $(P<0.01$ or less) when the concentration of these chelators was increased to $1 \mathrm{mM}$. At the concentration of $1.6 \mathrm{mM}$ of these chelators, the ionized calcium levels were less than $0.1 \mathrm{mM}$. The magnesium concentration gradually decreased $(P<0.05$ or less) when the EDTA concentration was increased to $1.6 \mathrm{mM}$.

Figures 2 and 3 show the effects of EDTA (1 $\mathrm{mM})$ and EGTA $(1 \mathrm{mM})$ on potassium $(8 \mathrm{mM})-$, AII (10 nM)- and ACTH (10 nM)-stimulated aldosterone production in bovine adrenal glomerulosa cells, respectively. The levels of agonist-stimulated aldosterone production in the presence of EDTA were significantly $(P<0.001)$ increased when compared with those in the absence

Table 1. Levels of sodium, potassium, magnesium and ionized calcium in the incubation media in the presence of graded concentrations of the calcium chelators (EGTA and EDTA)

\begin{tabular}{lcccc}
\hline EGTA (mM) & 0 & 0.6 & 1.0 & 1.6 \\
\hline sodium (mM) & $144 \pm 1$ & $145 \pm 2$ & $144 \pm 1$ & $146 \pm 1$ \\
potassium (mM) & $4.10 \pm 0.01$ & $4.10 \pm 0.01$ & $4.10 \pm 0.01$ & $4.10 \pm 0.01$ \\
magnesium (mM) & $0.62 \pm 0.01$ & $0.62 \pm 0.01$ & $0.62 \pm 0.01$ & $0.62 \pm 0.01$ \\
calcium (mM) & $0.93 \pm 0.06$ & $0.48 \pm 0.01^{\mathrm{b}}$ & $0.16 \pm 0.01^{\mathrm{c}}$ & $<0.1$ \\
\hline EDTA (mM) & 0 & 0.6 & 1.0 & 1.6 \\
\hline sodium (mM) & $144 \pm 1$ & $146 \pm 2$ & $146 \pm 1$ & $147 \pm 2$ \\
potassium (mM) & $4.10 \pm 0.01$ & $4.10 \pm 0.01$ & $4.10 \pm 0.01$ & $4.10 \pm 0.01$ \\
magnesium (mM) & $0.62 \pm 0.01$ & $0.40 \pm 0.01^{\mathrm{a}}$ & $0.30 \pm 0.01^{\mathrm{c}}$ & $0.17 \pm 0.01^{\mathrm{c}}$ \\
calcium (mM) & $0.99 \pm 0.07$ & $0.49 \pm 0.01^{\mathrm{b}}$ & $0.19 \pm 0.01$ & $<0.1$ \\
\hline
\end{tabular}

Values are expressed as the mean \pm SEM of triplicated samples from a representative experiment. ${ }^{a} P<0.05 v$ s. corresponding basal value without the calcium chelator. ${ }^{b} P<0.01$ vs. corresponding basal value without the calcium chelator. ${ }^{c} P<0.001$ vs. corresponding basal value without the calcium chelator. 


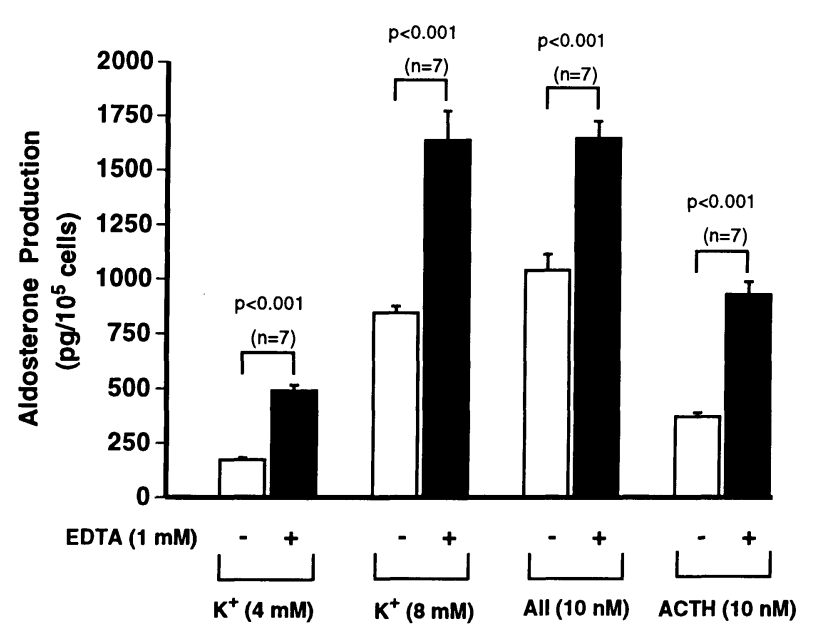

Fig. 2. Effect of the calcium chelator EDTA on basal and agonist (potassium, $8 \mathrm{mM}$; AII, $10 \mathrm{nM}$; ACTH, 10 $\mathrm{nM}$ )-stimulated aldosterone production in bovine adrenal glomerulosa cells. Values are expressed as the mean \pm SEM of seven separate experiments.

of EDTA (Fig. 2). Similarly, the levels of agoniststimulated aldosterone production in the presence of EGTA were significantly ( $P<0.01$ or less) increased when compared with those in the absence of EGTA (Fig. 3).

\section{Discussion}

The present study shows that the addition of the calcium chelators EDTA and EGTA to an extracellular solution potentiates basal and stimulated aldosterone production in bovine adrenal glomerulosa cells in vitro.

In the present study, although administration with EDTA, but not EGTA, was associated with a reduction in the level of magnesium in the incubation medium, both the chelators potentiate basal aldosterone production in the cells. We previously showed [7] that basal aldosterone production was unaltered in the cells incubated in the medium containing from 0.2 to $2.4 \mathrm{mM}$ calcium chloride in the absence of EGTA. Moreover, it is unlikely that EGTA alone can directly stimulate aldosterone production since the presence of EGTA without calcium in the incubation media has been reported to have no steroidogenic effect in vitro $[1-3,5,9]$. Taken together, these findings suggest that the addition of EDTA as well as EGTA to an

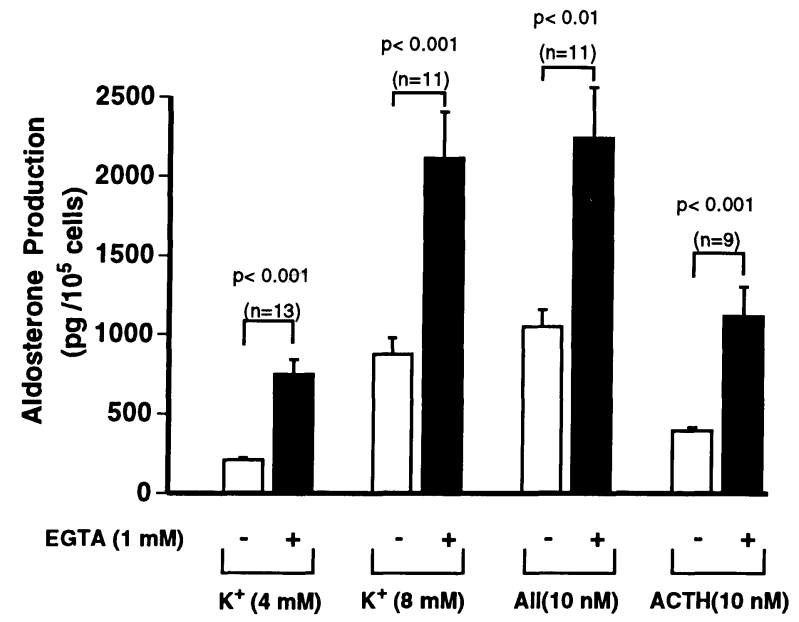

Fig. 3. Effect of the calcium chelator EGTA on basal and agonist (potassium, $8 \mathrm{mM}$; AII, $10 \mathrm{nM}$; ACTH, 10 $\mathrm{nM}$ )-stimulated aldosterone production in bovine adrenal glomerulosa cells. Values are expressed as the mean $\pm S E M$ of nine to thirteen separate experiments.

extracellular solution can stimulate basal aldosterone production in bovine adrenal glomerulosa cells in vitro.

AII and potassium are known to stimulate aldosterone production through intracellular $\mathrm{Ca}^{2+}$ / calmodulin-dependent steps [10,11]. Moreover, no additivity in steroidogenesis has been reported when canine adrenal glomerulosa cells are stimulated by both supramaximal steroidogenic concentrations of AII and potassium [12]. On the other hand, we previously suggested the involvement of $\mathrm{Ca}^{2+} /$ calmodulin-dependent steps in the EGTA-induced aldosterone increase [7]. In the present study, however, the administration with EDTA or EGTA potentiated both potassium- and AII-stimulated aldosterone production. The present results cannot therefore be explained by saying that the calcium chelators and these stimuli (AII and potassium) act through a common mechanism in the cells. The lack of an inhibitory effect of $\mathrm{H7}$ on the EDTA- and EGTA-induced increase in aldosterone production suggests that protein kinase $C$ may not be involved in the mechanism(s) of this increase. The present results further imply that another mechanism(s) in addition to $\mathrm{Ca}^{2+} /$ calmodulin-dependent steps is involved in the potentiation. It seems unlikely that the action of these calcium chelators is cAMPdependent since cyclic AMP production was not 
stimulated by the addition of EDTA or EGTA to the extracellular solution. Moreover, the maximum stimulation of aldosterone production by ACTH $(10 \mathrm{nM})$ was potentiated in the presence of these chelators in the cells.

In conclusion, basal and the agonist-stimulated aldosterone production were potentiated by the addition of EDTA and EGTA to the extracellular solution. The increase in basal aldosterone production in the presence of EDTA $(1 \mathrm{mM})$ and EGTA ( $1 \mathrm{mM})$ was completely inhibited by the voltage-dependent calcium channel antagonist nifedipine $(1 \mu \mathrm{M})$ or the calmodulin antagonist pimozide $(1 \mu \mathrm{M})$. The potentiation of the agoniststimulated aldosterone production, however, does not seem to be $\mathrm{Ca}^{2+} /$ calmodulin-dependent nor
cAMP-dependent. Although we cannot explain the mechanism(s) exactly from the present study, these findings suggest that there may be another mechanism of regulation of aldosterone production rather than well-known systems, including cAMPdependent, $\mathrm{Ca}^{2+} /$ calmodulin-dependent and protein kinase $C$ dependent processes. Further experiments investigating the exact role of EDTA and EGTA must be needed.

\section{Acknowledgements}

This study was supported in part by a grant for Collaborative Research from Kanazawa Medical University (C95-4).

\section{References}

1. Fakunding JL, Chow R, Catt K (1979) The role of calcium in the stimulation of aldosterone production by adrenocorticotropin, angiotensin II, and potassium in isolated glomerulosa cells. Endocrinology 105: 327-333.

2. Foster R, Lobo MV, Rasmussen H, Marusic ET (1981) Calcium: Its role in the mechanism of action of angiotensin II and potassium in aldosterone production. Endocrinology 109: 2196-2201.

3. Kojima I, Kojima K, Rasmussen H (1985) Effects of ANG II and $\mathrm{K}^{+}$on Ca efflux and aldosterone production in adrenal glomerulosa cells. $A m J$ Physiol 248: E36-E43.

4. Hausdorff WP, Aguilera G, Catt KJ (1986) Selective enhancement of angiotensin II- and potassiumstimulated aldosterone secretion by the calcium channel agonist BAY K 8644. Endocrinology 118: 869874.

5. Ganguly A, Chiou S, Fineberg NS, Davis JS (1992) Greater importance of $\mathrm{Ca}^{2+}$-calmodulin in maintenance of ANG II- and $\mathrm{K}^{+}$-mediated aldosterone secretion: Lesser role of protein kinase C. Biochem Biophys Res Commun 182: 254-261.

6. Chiu AT, Freer RJ (1979) Angiotensin-induced steroidogenesis in rabbit adrenal: Effects of $\mathrm{pH}$ and calcium. Mol Cell Endocrinol 13: 159-166.
7. Kigoshi $\mathrm{T}$, Nakano $\mathrm{S}$, Okamoto $\mathrm{H}$, Ishii $\mathrm{T}$, Kitazawa M, Sugai T, Uchida K, Morimoto S (1995) Lowering extracellular calcium concentrations with the calcium chelator EGTA stimulates basal aldosterone production in bovine adrenal glomerulosa cells in vitro. Endocrinol Metab 2: 185-191.

8. Kigoshi T, Imaizumi N, Azukizawa S, Yamamoto I, Uchida K, Konishi F, Morimoto S (1986) Effects of angiotensin II, adrenocorticotropin, and potassium on aldosterone production in adrenal zona glomerulosa cells from streptozotocin-induced diabetic rats. Endocrinology 118: 183-188.

9. Schiffrin EL, Lis M, Gutkowska J, Genest J (1981) Role of $\mathrm{Ca}^{2+}$ in response of adrenal glomerulosa cells to angiotensin II, ACTH, $\mathrm{K}^{+}$, and ouabain. $\mathrm{Am}$ J Physiol 241: E42-E46.

10. Wilson JX, Aguilera G, Catt KJ (1984) Inhibitory actions of calmodulin antagonists on steroidogenesis in zona glomerulosa cells. Endocrinology 115: 1357-1363.

11. Quinn SJ, Williams GH (1988) Regulation of aldosterone secretion. Ann Rev Physiol 50: 409-426.

12. Fujita K, Aguilera G, Catt KJ (1979) The role of cyclic AMP in aldosterone production by isolated zona glomerulosa cells in vitro. J Biol Chem 254: 8567-8574. 